\title{
Comunicación

\section{Quiebres de un proceso inacabado: mirada a la legislación de la comunicación social en México desde un enfoque sociopolítico}

\author{
SALVADOR DE LEÓN VÁZQUEZ1
}

Las reformas a la Ley Federal de Radio y Televisión (LFRyT) aprobadas por el Congreso de la Unión, previas a la elección presidencial del 2006, nos dio un panorama de cómo se ha construido la correlación de fuerzas entre los concesionarios de los medios electrónicos y los representantes de los poderes democráticos instituidos, específicamente la LIX Legislatura federal. La iniciativa a la cual se conoció como "Ley Televisa", por las implicaciones de blindaje empresarial al duopolio televisivo que opera en México, al favorecer a los concesionarios actuales para incrementar su participación en el espectro radioeléctrico e incursionar en los servicios de banda ancha (que incluyen telefonía, internet y televisión), quedó de esta manera elevada al rango de legislación vigente.

Con desencanto, quienes nos hemos preocupado por llegar a obtener los alcances de la democracia en materia de comunicación social,

1 Universidad Autónoma de Aguascalientes.

Correo electrónico: sdeleon@correo.uaa.mx 
pudimos observar la capacidad de cabildeo de los poderes fácticos para lograr que la totalidad de la Cámara de Diputados y la mayoría de la de Senadores les otorgaran el apoyo. En contraposición se encontraba la propuesta desarrollada por la Comisión de Comunicaciones y Transportes de la cámara alta, presidida por el ex senador panista Javier Corral, que ofrecía condiciones que empoderaban a la ciudadanía y a las instituciones frente a los empresarios de los medios electrónicos, y que simplemente fue rechazada.

El asunto dista mucho de ser únicamente una discusión referida a la regulación legal de la operación de la radiodifusión en México, que es en este momento su condición más visible, sino que se inscribe en un largo y complejo proceso de intentar establecer una reglamentación clara sobre la comunicación social en nuestro país, proceso que inició desde el sexenio echeverrista cuando el derecho a la información fue incorporado al artículo $6^{\circ}$ del texto de nuestra Constitución Política. La historia que se ha construido a partir de entonces muestra las condiciones estructurales en las que se inserta la participación de las empresas de medios en nuestro país, en relación con los poderes instituidos y con los sectores de la producción económica.

Para entender y eventualmente incidir sobre esta situación es necesario estudiarla, y desde mi punto de vista las reflexiones que presenta Roberto Gutiérrez López en su libro Información y democracia. Los medios de comunicación social y su influencia sobre la política. El caso de México, nos ayudan a acercarnos con una mirada construida desde el campo académico del análisis sociopolítico.

Para Gutiérrez, la necesidad de contar con una legislación clara y consensada por todos los sectores sociales, que garantice el derecho a la información y, al mismo tiempo, que brinde certidumbre sobre el ejercicio responsable de la libertad de expresión (los dos grandes temas que subyacen a este debate), es fundamental para la consolidación de la democracia en nuestro país.

Un espacio comunicativo plural que otorgue condiciones para la deliberación abierta y para que la ciudadanía tenga acceso a la información necesaria para la responsable toma de decisiones, es visto como un escenario deseable que contribuya a la construcción de condiciones de equidad, de justicia y de responsabilidad social. 
HISTORIA FRACTURADA

DE LOS ESFUERZOS POR REGULAR

Con el objeto de situar históricamente la discusión, el autor se da a la tarea de reconstruir el proceso del debate sobre la legislación en la materia. Su revisión nos coloca frente a los efectos políticos de los avances y retrocesos en este renglón, y que han permitido lograr la configuración que hoy mantenemos en México respecto a la operación de los medios de comunicación, principalmente los electrónicos.

Gutiérrez toma como punto de partida la "Agenda para la discusión de la reforma política del Estado" propuesta el 15 de mayo de 1995 (p. 17), durante el sexenio zedillista, donde el problema de la regulación de la comunicación social era considerada como un tema, aunque marginal, ligado al capítulo de la participación ciudadana.

El autor sostiene que es partir de la implementación de la discusión para la reforma del Estado que el tema de la comunicación social penetra en la agenda, primero de la sociedad civil organizada y después en la legislativa, con mayor fuerza y sistematicidad. En este contexto, la discusión para la reforma del Estado rindió frutos significativos para la consolidación de la democracia, como los alcanzados en el rubro electoral. Pero, a juicio de Gutiérrez, una verdadera conformación democrática para México tiene que pasar por una reformulación de las "reglas del juego" en el ejercicio mediático, a fin de otorgar una base de participación plural y equitativa en la deliberación democrática.

El proceso se desarrolló entre una serie de tensiones, donde los empresarios mediáticos echaron a andar su maquinaria ideológica acusando de pretender construir mecanismos de control sobre la libertad de expresión; calificaron con el apelativo de "Ley mordaza" a los esfuerzos que se realizaban por acotar el poder de los medios electrónicos mediante una delimitación legal del ejercicio de la comunicación social. La iniciativa de la Ley de comunicación social sucumbió ante esas presiones, ocasionando que el tema fuera pospuesto en la agenda legislativa.

En el sexenio foxista, el autor reconoce la división del esfuerzo por regular el ejercicio de la comunicación en nuestro país en dos vertientes: la relacionada con la defensa de la libertad de expresión con responsabilidad, y la referente al derecho a la información, como dos caras de 
una misma moneda. Los actores políticos de este periodo parecen haber puesto más atención a la segunda, de la cual también hubo dos distinticiones: el derecho de acceso a la información pública (delimitado a la obligación del Estado de ofrecer información de su actividad pública), y el derecho a estar informado sobre el acontecer social a través de las instancias pertinentes (aquí entra la labor informativa de los medios de comunicación).

El esfuerzo se centró en la idea del acceso a la información pública, por considerarse como un tema políticamente correcto, con el cual convenían los diferentes actores sociopolíticos: representaba una obligación de los poderes (el Ejecutivo federal, principalmente) para la rendición de cuentas, brindaba a los trabajadores de los medios (los periodistas), instrumentos para exigir información al Estado, y contribuía a transparentar acciones de cara a la ciudadanía. Por lo tanto no era comprometedora más que con el Estado mismo, que asumió esa responsabilidad. Sin embargo, hubo discusiones respecto a las propuestas desarrolladas por la sociedad civil, sintetizadas por la declaratoria del Grupo Oaxaca, que fue el verdadero promotor de esta ley al reivindicar el derecho de acceso a la información pública. La discusión era por condiciones que el grupo consideraba importantes para ser instaladas en el documento de la ley, y que estaban ausentes, y también por la autoría de la iniciativa.

Respecto a la necesidad de reglamentar la actuación de los medios de comunicación en términos de contenidos, otorgamiento de concesiones, límites responsables de la libertad de expresión, entre otras cosas, la salida recurrente ha sido la de la alusión a los códigos éticos de autorregulación de los propios medios, con la problemática de que son los empresarios quienes determinan los alcances de estos códigos sin referencia a una regla general.

\section{EFECTOS POLÍTICOS}

La segunda parte del libro se enfoca en los principales efectos políticos que derivan del actual régimen de comunicación social en México, pero, principalmente, del proceso de su conformación. El esencial es la actitud pragmática con la que han participado los operadores políticos en la discusión sobre la legislación en materia de comunicación social. 
Han actuado en función de la rentabilidad política (principalmente su visibilización pública) que otorga el colocarse del lado de los concesionarios de los medios, sin importar el alcance cortoplacista de estas negociaciones.

El problema fundamental en esta situación, nos dice Gutiérrez, es la forma en que los medios electrónicos se insertan en la vida política de México:

son actores que usufructúan un bien público, el espacio electromagnético, que generan efectos políticos y sociales considerables y que, sin embargo, no están sujetos a un marco de responsabilidades y de rendición de cuentas acorde con la trascendencia y el alcance de una actividad que hace mucho tiempo dejó de ser únicamente, si es que alguna vez lo fue, vehículo de "información y entretenimiento" (p. 128).

De tal manera que los efectos generados por la falta de mecanismos legales que delimiten la actuación de los medios de comunicación, inciden directamente en la construcción de una cultura política, con la injerencia que esto tiene en relación con la formación de identidades políticas individuales y colectivas, toda vez que el papel de los medios de comunicación tiene amplios alcances en la visibilidad e invisibilidad de proyectos políticos determinados (y por lo regular sujetos a los propios intereses de los concesionarios).

En el momento en que Gutiérrez hace el corte de su investigación, a mediados del sexenio de Vicente Fox, todavía no aparecía en escena el asunto de la Ley Televisa, aunque ya había actores de la sociedad civil (individuales y colectivos) y legisladores que pugnaban por una modificación al esquema de reglamentación de la actividad de los medios de comunicación.

Sin embargo, en su análisis, Gutiérrez ya identificaba la tendencia de la política foxista en este rubro, por lo que en la última página de sus conclusiones advierte:

nuestra clase política cometería un grave error si optara de nuevo por la postergación de una reglamentación de los medios electrónicos tan urgente como necesaria (p. 196). 
Urgente y necesaria para evitar situaciones como la protagonizada por TV Azteca y CNI-Canal 40, donde la primera de las televisoras tomó atribuciones que corresponden al Poder Judicial, o la manera en cómo los medios electrónicos presionaron para la aprobación de las reformas a la LFRyT aun a costa de vulnerar las atribuciones del Ejecutivo federal en torno a las concesiones y a las instituciones de medios públicos para satisfacer intereses económicos de los medios privados.

Finalmente, una de las propuestas del autor para que se contribuya a especificar un esquema en el que pueda construirse una legislación de la actividad mediática, sin cortapisas a la libertad de expresión pero asumiendo responsabilidad en su ejercicio, sería una combinación entre reglamentación y autorregulación, pues por medio de la primera se contribuye a la construcción de ciudadanía democrática mediante la conformación de un derecho positivo con normas vinculantes en relación con la comunicación social, mientras que por la autorregulación se estaría en consonancia con las conquistas liberales relacionadas con el ejercicio de las libertades y derechos individuales, con sus respectivas responsabilidades.

\section{ASPECTOS CONCEPTUALES DE LA OBRA}

Hemos dicho que el autor presenta su reflexión desde el enfoque del análisis sociopolítico. En este sentido, construye su objeto de estudio sobre la discusión política en torno al régimen de comunicación social para entender las repercusiones que tiene en la dinámica social, y en la estructura política del país (p. 119).

La construcción que hace del ámbito político, a lo largo de la discusión en la que el autor se inscribe, se relaciona con las instancias institucionalizadas, específicamente de los poderes Legislativo y Ejecutivo, y no se trae al debate teórico la ampliación del espacio político ampliado, es decir, no considera las esferas públicas civiles, en las que también existen actores sociopolíticos que han reivindicado el derecho a la información y la exigencia del ejercicio de la libertad de expresión con responsabilidad.

Si bien dichos actores no son ignorados, pues a lo largo del trabajo hay menciones a académicos y a la sociedad civil organizada, no 
se estudia con suficiente profundidad el efecto que estos actores y los movimientos sociales en los que se inscriben significaron para los pocos avances que se han logrado, tales como poner en la agenda de la reforma del Estado la propuesta de Ley de comunicación social, que no prosperó, o la injerencia del Grupo Oaxaca en la formulación de la Ley de transparencia y acceso a la información pública.

Tampoco hay un abordaje suficiente de los actores mediáticos que sí asumieron la necesidad de una reforma en la legislación de medios, tales como algunos públicos (Canal 11 del IPN) o impresos (La Jorna$d a$ ), que si bien manejaban sus intereses particulares, la visión que le otorga estar "del otro lado", del lado de los medios, también significó contrapesos importantes en las discusiones al respecto.

Por lo que se observa, la concepción de espacio político a la que se adscribe esta reflexión se enmarca en los mecanismos procedimentales de la democracia, como la formulación de leyes, pero quedan al margen otros contextos que son fundamentales para que tales proyectos cuajen, y que por lo regular están fuera de esas líneas procedimentales por tener una naturaleza más dialógica en lo social.

Sin embargo, la sujeción a este entendimiento de la política le otorga también su rigor metodológico, en términos de asirse a ciertas condiciones objetivas de la realidad, como los contextos institucionales en los que se da la deliberación política que es, a final de cuentas, una de las principales características de las democracias representativas contemporáneas. La obra reseñada es importante porque representa una estrategia de fijación del discurso, y es selectiva de una dimensión metodológica desde la cual mirar una realidad que es complicada en sí misma. 
